УДК 616.895.8:616.89-008.441.13:611.018.74

Для цитирования: Сахаров А.В., Озорнин А.С., Голыгина С.Е. Некоторые показатели микроциркуляции крови у пациентов при острой шизофрении и алкогольном делирии в сравнительном аспекте. Сибирский вестник психиатрии и наркологии. 2019; 2 (103): 13-21. https://doi.org/10.26617/1810-3111-2019-2(103)-13-21

\title{
Некоторые показатели микроциркуляции крови у пациентов при острой шизофрении и алкогольном делирии в сравнительном аспекте
}

\section{Сахаров А.В.', Озорнин А.С. ${ }^{1,2}$, Голыгина С.Е.',3}

1 Читинская государственная медииинская академия

Россия, 672000, Чита, ул. Горького, 39-а

${ }^{2}$ Краевая клиническая психиатрическая больнича имени В.Х. Кандинского

Россия, 672042, Чита, Окружной проезд, 3

з Забайкальский краевой наркологический диспансер

Россия, 672039, Чита, ул. Верхоленская, 1

\section{PEЗЮME}

Патогенез нарушений микроциркуляции при психических и наркологических расстройствах изучен недостаточно. Целью работы стало изучение состояния микроциркуляции крови методом лазерной доплеровской флоуметрии у больных в психотическом состоянии при шизофрении и при синдроме отмены алкоголя с делирием в сравнительном аспекте. Было обследовано с помощью лазерного анализатора кровотока 40 пациентов с шизофренией и 25 пациентов с алкогольным делирием в остром психотическом состоянии и через 2 недели терапии. Контрольную группу составили 35 здоровых добровольцев. Установлены общие системные нарушения микроциркуляции у пациентов в остром психотическом состоянии при шизофрении и при алкогольном делирии в виде ускорения кровотока в единицу времени и чрезмерного усиления локальных механизмов его регуляции. При этом регистрируемые изменения показателей микроциркуляции сохранялись даже через 2 недели терапии, оказывая, вероятно, более длительное патологическое действие, нежели само течение острого психоза.

Ключевые слова: шизофрения, алкоголизм, параноидная шизофрения, алкогольный делирий, микроциркуляция, эндотелиальная дисфункция.

\section{ВВЕДЕНИЕ}

Во второй половине XX века активно разрабатывалась гипотеза об общности некоторых механизмов в развитии психических заболеваний, особенно в период возникновения психотических расстройств, как эндогенной, так и экзогенной этиологии [1]. В последующем общими проявлениями стали сопровождающие эти заболевания когнитивные расстройства и регистрируемая соматическая патология.

Безусловно, основы данных процессов, например при хронической алкогольной интоксикации, были весьма понятны [2] и давно описаны патологоанатомами [3]. Объективизированы структурные изменения во внутренних органах, введено понятие алкогольной болезни $[4,5]$, сформировано представление о механизмaх повреждающего действия алкоголя [2]. Вполне очевидно, что кровеносные сосуды страдают при злоупотреблении алкоголем в первую очередь, так как осуществляют транспорт алкоголя ко всем органам. Установлено системное поражение сосудистых стенок, в первую очередь микроциркуляторного русла, при алкоголизме [6, 7, 8, 9, 10, 11].

Исследователями изучались различные лабораторные показатели эндотелиальной дисфункции при употреблении спиртных напитков $[12,13,14,15,16,17]$, хотя единой точки зрения на происходящие при этом процессы так и не сформировано [18, 19].

Что касается пациентов с шизофренией, то в последние десятилетия отмечен рост смертности от сердечно-сосудистых заболеваний: выявлено превышение этой причины смертности у больных шизофренией в 2 раза над показателями в общей популяции [20]. Накапливаются данные о развитии у лиц данной группы множества соматических заболеваний, таких как атеросклероз, гипертоническая болезнь, ишемическая болезнь сердца, цереброваскулярные заболевания, сахарный диабет и другие $[21,22,23]$. Сложившаяся ситуация традиционно объяснялась ростом встречаемости метаболических осложнений у пациентов с шизофренией, получающих антипсихотики второго поколения [24, 25]. 
В то же время некоторые авторы указывают и на другие возможные причины повышенного риска сердечно-сосудистых заболеваний при шизофрении - эндотелиальную дисфункцию [22] и дисфункцию вегетативной нервной системы [26], особенно у пациентов в остром психотическом состоянии. При этом имеющиеся исследования на эту тематику единичны, в них установлены неблагоприятные изменения показателей синтазы оксида азота [27], оксида азота и эндотелина-1 [28], реактивности микроциркуляции с помощью метода реактивной (постокклюзионной) гиперемии [29].

Несмотря на значимость представленной информации, точные патофизиологические механизмы нарушений микроциркуляции при шизофрении и злоупотреблении спиртными напитками по-прежнему не установлены.

Между тем, на наш взгляд, объективно регистрируемое повреждение гематоэнцефалического барьера и развитие висцеропатий у пациентов в любом остром психотическом состоянии обусловлено, в том числе, вероятной общностью патогенеза происходящих системных нарушений в микроциркуляторном русле.

Следовательно, определение клиникопрогностического значения нарушений микроциркуляции требует дальнейшего изучения в сравнительном аспекте при психотических расстройствах разной этиологии (например, при эндогенных и экзогенных психозах).

\section{ЦЕЛЬ ИССЛЕДОВАНИЯ}

Изучение состояния микроциркуляции крови методом лазерной доплеровской флоуметрии у пациентов в психотическом состоянии при параноидной форме шизофрении и при синдроме отмены алкоголя с делирием в сравнительном аспекте.

\section{МАТЕРИАЛЫ И МЕТОДЫ}

На базе отделения первого психотического эпизода Краевой клинической психиатрической больницы имени В.Х. Кандинского сплошным методом было обследовано 40 пациентов в возрасте от 18 до 40 лет (средний возраст составил $28,6 \pm 0,9$ года) с диагнозом «параноидная шизофрения» (F20.0). Аналогично на базе Забайкальского краевого наркологического диспансера обследовано 25 человек с диагнозом «синдром отмены алкоголя с делирием» (F10.40) в возрасте от 25 до 40 лет (средний возраст $34,1 \pm 1,2$ года). Исследование проводилось в динамике: перед началом лечения в остром психотическом состоянии и через 2 недели стандартной терапии.
Критериями включения в исследование являлись возраст от 18 до 40 лет, отсутствие грубой соматической патологии, такой как вирусные гепатиты, цирроз печени, заболевания сердца, гипертоническая болезнь и симптоматические артериальные гипертензии, эндокринная патология, злокачественные новообразования, ХОБЛ с дыхательной недостаточностью, хроническая почечная и печеночная недостаточность, воспалительные заболевания любой этиологии (острые, хронические в стадии обострения).

Контрольную группу составили 35 здоровых добровольцев в возрасте от 21 до 40 лет. Исследуемые и контрольная группы не имели гендерных и возрастных различий $(\mathrm{p}>0,05)$. Все обследованные предоставили добровольное информированное согласие на участие в исследовании.

Для оценки состояния микроциркуляторного русла использовался неинвазивный метод лазерной доплеровской флоуметрии (ЛДФ) с помощью лазерного анализатора кровотока «ЛАКК-02» с компьютерным интерфейсом (НПП «ЛАЗМА», Москва). Датчик устанавливался в нижней трети предплечья по наружной поверхности на 4 см выше основания шиловидных отростков локтевой и лучевой костей. Выбор этой области обусловлен тем, что она бедна артериоло-венулярными анастомозами, поэтому в большей степени отражает кровоток в нутритивном русле. Все исследования осуществлялись в положении лежа, рука находилась на уровне сердца; ЛДФ-граммы регистрировались в течение 3 минут. Оценивались показатель микроциркуляции (ПМ), среднеквадратическое отклонение $(\sigma)$ и коэффициент вариации $(\mathrm{Kv})$. Параметр ПМ отражает величину потока крови в интервал времени, выражаемую в перфузионных единицах (пф.ед.); $\sigma$ и $\mathrm{Kv}-$ вариабельность микрососудистого кровотока. Для оценки функционального состояния регуляторного звена микроциркуляции использовался Вейвлет-анализ, с помощью которого рассчитывались показатели шунтирования (ПШ), нейрогенного (НТ) и миогенного (МТ) тонуса сосудов [30].

Статистическая обработка полученных результатов осуществлялась с применением пакета анализа Microsoft Excel 2007 и пакета прикладных статистических программ «Statistica10». При описании количественных результатов исследования использовали медиану со стандартным отклонением (Me $\pm \mathrm{SD})$. 
Полученные данные представлены в виде медианы (Ме) и интерквартального (25-й и 75-й перцентили) интервала. Для сравнения двух независимых выборочных совокупностей применяли непараметрический U-критерий МаннаУитни. Для сравнения связанных между собой показателей (одна группа в динамике) использовали непараметрический критерий W-
Вилкоксона. Различия считали достоверными при показателе $\mathrm{p}<0,05$.

\section{РЕЗУЛЬТАТЫ И ОБСУЖДЕНИЕ}

Установлено, что у пациентов с шизофренией в остром психотическом состоянии до лечения общий показатель микроциркуляции (ПМ) не отличался от контрольных значений (табл. 1), у больных алкоголизмом в делирии он превышал значения контрольной группы в 1,4 раза $(\mathrm{p}=0,0000)$.

Т а бл и ц а 1

Показатели микроциркуляции крови здоровых и пациентов с острой параноидной шизофренией и алкогольным делирием до лечения

\begin{tabular}{|c|c|c|c|c|}
\hline $\begin{array}{c}\text { Показатель } \\
\text { (ед. измерения) }\end{array}$ & Группа & $\operatorname{Me}(25 ; 75)$ & \multirow[t]{2}{*}{$\begin{array}{c}\text { Критерий Манна-Уитни } \\
\text { с группой контроля }\end{array}$} & \multirow[t]{2}{*}{$\begin{array}{c}\text { Критерий Манна-Уитни } \\
\text { между группами }\end{array}$} \\
\hline \multirow[t]{3}{*}{ ПМ (пф.ед.) } & Контроль $(\mathrm{n}=35)$ & $6,63(5,91 ; 7,22)$ & & \\
\hline & $\mathrm{F} 20.0(\mathrm{n}=40)$ & $6,88(5,13 ; 8,74)$ & 1,$04075 ; p=0,297993$ & \multirow[t]{2}{*}{3,$90412 ; \mathbf{p}=\mathbf{0 , 0 0 0 0 9 5}$} \\
\hline & F10.40 $(n=25)$ & $9,37(7,78 ; 10,91)$ & 5,$45438 ; \mathbf{p}=\mathbf{0 , 0 0 0 0 0 0}$ & \\
\hline \multirow[t]{3}{*}{$\mathrm{Kv}(\%)$} & Контроль $(\mathrm{n}=35)$ & $11,51(7,08 ; 26,86)$ & & \\
\hline & F20.0 $(n=40)$ & $61,59(38,73 ; 80,86)$ & 6,$10112 ; \mathbf{p}=\mathbf{0 , 0 0 0 0 0 0}$ & \multirow[t]{2}{*}{5,$50514 ; \mathbf{p}=\mathbf{0 , 0 0 0 0 0 0}$} \\
\hline & F10.40 $(n=25)$ & $15,53(11,21 ; 33,4)$ & 1,$26151 ; p=0,207127$ & \\
\hline \multirow[t]{3}{*}{ б (пф.ед.) } & Контроль $(\mathrm{n}=35)$ & $0,78(0,52 ; 1,60)$ & & \\
\hline & F20.0 $(n=40)$ & $4,92(2,56 ; 6,71)$ & 6,$25511 ; \mathbf{p}=\mathbf{0 , 0 0 0 0 0 0}$ & \multirow[t]{2}{*}{3,$52355 ; \mathbf{p}=\mathbf{0 , 0 0 0 4 2 6}$} \\
\hline & F10.40 $(n=25)$ & $2,02(0,88 ; 3,51)$ & 3,$15742 ; \mathbf{p}=\mathbf{0 , 0 0 1 5 9 2}$ & \\
\hline \multirow[t]{3}{*}{ ПШ } & Контроль $(\mathrm{n}=35)$ & $1,07(0,97 ; 1,35)$ & & \\
\hline & F20.0 $(n=40)$ & $0,92(0,83 ; 1,09)$ & 2,$70807 ; \mathbf{p}=\mathbf{0 , 0 0 6 7 6 8}$ & \multirow[t]{2}{*}{1,$92253 ; p=0,054539$} \\
\hline & F10.40 $(n=25)$ & $1,09(0,92 ; 1,39)$ & 0,$10209 ; p=0,918687$ & \\
\hline \multirow[t]{3}{*}{ HT } & Контроль $(\mathrm{n}=35)$ & $1,90(1,77 ; 2,34)$ & & \\
\hline & F20.0 $(n=40)$ & $2,09(1,91 ; 2,90)$ & 2,$24080 ; \mathbf{p}=\mathbf{0 , 0 2 5 0 4 0}$ & \multirow[t]{2}{*}{3,$12986 ; \mathbf{p}=\mathbf{0 , 0 0 1 7 4 9}$} \\
\hline & F10.40 $(n=25)$ & $1,81(1,60 ; 2,08)$ & 1,$56048 ; p=0,118648$ & \\
\hline \multirow[t]{3}{*}{ MT } & Контроль $(\mathrm{n}=35)$ & $2,21(1,79 ; 2,71)$ & & \\
\hline & $\mathrm{F} 20.0(\mathrm{n}=40)$ & $2,13(1,88 ; 2,75)$ & 0,$29205 ; p=0,770251$ & \multirow[t]{2}{*}{0,$80051 ; p=0,423416$} \\
\hline & F10.40 $(n=25)$ & $2,01(1,86 ; 2,27)$ & 1,$00629 ; p=0,314217$ & \\
\hline
\end{tabular}

П р и м е ч н и е: жирным шрифтом выделены значимые результаты.

Через 2 недели терапии при шизофрении показатель микроциркуляции увеличивался $(\mathrm{p}=0,002)$, в результате превышал контрольные значения в 1,2 раза $(\mathrm{p}=0,001)$. При алкогольном делирии в динамике, наоборот, общий показатель микроциркуляции крови снизился в 1,1 раза $(\mathrm{p}=0,02)$, хотя сохранялось существенное отличие от показателя в контрольной группе $(\mathrm{p}=0,001)$.

Полученные результаты отражают выраженное ускорение потока крови в интервал времени через микроциркуляторное русло у пациентов при синдроме отмены алкоголя с делирием, которое сохраняется даже после купирования психоза (табл. 2-3). При острой шизофрении таких существенных изменений не наблюдается.

В состоянии острого психотического расстройства при шизофрении было зарегистрировано значимое увеличение (в 5,3 раза; $\mathrm{p}=0,0000)$ коэффициента вариации $(\mathrm{Kv})$ в срав- нении с контролем. При алкогольном делирии таких изменений не отмечалось, показатель не отличался от контрольных значений (табл. 1).

В процессе лечения при шизофрении значение коэффициента вариации практически не изменилось, тогда как в группе пациентов после выхода из алкогольного психоза этот показатель вырос в 1,4 раза ( $\mathrm{p}=0,04)$, отмечено превышение в 1,9 раза контрольных значений $(\mathrm{p}=0,04)$, хотя он был значимо ниже, чем у больных шизофренией ( $\mathrm{p}=0,0000)$ (табл. 2-3).

При этом коэффициент вариации является отражением воздействия на микроциркуляторный кровоток активных механизмов регуляции. Вероятно, при параноидной шизофрении в остром психотическом состоянии изначально происходит чрезмерное усиление локальных механизмов регуляции микрокровотока, что является неблагоприятным фактором и косвенно может говорить о дисбалансе между медиаторами, обеспечивающими оптимальное тече- 
ние эндотелийзависимых процессов. При алкогольном делирии изначально каких-либо изменений не наблюдается, что может свидетельствовать о существенной недостаточности регуляторных процессов на уровне микроциркуляции при имеющихся зачастую объективных расстройствах гомеостаза. В то же время после перенесенного алкогольного делирия происходит усиление локальных механизмов регуляции микрокровотока, что может выступать неблагоприятным фактором, который при длительном воздействии может усугублять течение имеющихся соматических расстройств .

Показатели микроциркуляции крови здоровых и пациентов с острой параноидной шизофренией и алкогольным делирием в динамике через 2 недели

\begin{tabular}{|c|c|c|c|c|}
\hline $\begin{array}{c}\text { Показатель } \\
\text { (ед. измерения) }\end{array}$ & Группа & $\operatorname{Me}(25 ; 75)$ & \multirow[t]{2}{*}{\begin{tabular}{|c|} 
Критерий Манна-Уитни \\
с группой контроля
\end{tabular}} & \multirow[t]{2}{*}{$\begin{array}{c}\text { Критерий Манна- } \\
\text { Уитни между группами }\end{array}$} \\
\hline \multirow[t]{3}{*}{ ПМ (пф.ед.) } & Контроль (n=35) & $6,63(5,91 ; 7,22)$ & & \\
\hline & $\mathrm{F} 20.0(\mathrm{n}=40)$ & $7,90(6,22 ; 10,12)$ & 3,$15942 ; \mathbf{p}=\mathbf{0 , 0 0 1 5 8 1}$ & \multirow[t]{2}{*}{0,$03281 ; \mathrm{p}=0,973828$} \\
\hline & $\mathrm{F} 10.40(\mathrm{n}=25)$ & $8,45(6,53 ; 10,05)$ & 3,$17200 ; \mathbf{p}=\mathbf{0 , 0 0 1 5 1 4}$ & \\
\hline \multirow[t]{3}{*}{$\mathrm{Kv}(\%)$} & Контроль $(\mathrm{n}=35)$ & $11,51(7,08 ; 26,86)$ & & \\
\hline & F20.0 $(n=40)$ & $63,61(47,93 ; 86,15)$ & 6,$41972 ; \mathbf{p}=\mathbf{0 , 0 0 0 0 0 0}$ & \multirow[t]{2}{*}{4,$19283 ; \mathbf{p}=\mathbf{0 , 0 0 0 0 2 8}$} \\
\hline & $\mathrm{F} 10.40(\mathrm{n}=25)$ & $21,18(9,05 ; 53,49)$ & 2,$01987 ; \mathbf{p}=\mathbf{0 , 0 4 3 3 9 7}$ & \\
\hline \multirow[t]{3}{*}{ б (пф.ед.) } & Контроль $(\mathrm{n}=35)$ & $0,78(0,52 ; 1,60)$ & & \\
\hline & $\mathrm{F} 20.0(\mathrm{n}=40)$ & $3,82(2,14 ; 6,26)$ & 6,$86045 ; \mathbf{p}=\mathbf{0 , 0 0 0 0 0 0}$ & \multirow[t]{2}{*}{2,$42121 ; \mathbf{p}=\mathbf{0 , 0 1 5 4 6 9}$} \\
\hline & $\mathrm{F} 10.40(\mathrm{n}=25)$ & $2,32(0,68 ; 5,36)$ & 2,$63969 ; \mathbf{p}=\mathbf{0 , 0 0 8 2 9 9}$ & \\
\hline \multirow[t]{3}{*}{ ПШ } & Контроль (n=35) & $1,07(0,97 ; 1,35)$ & & \\
\hline & $\mathrm{F} 20.0(\mathrm{n}=40)$ & $1,06(0,84 ; 1,74)$ & 0,$15399 ; p=0,877619$ & \multirow[t]{2}{*}{0,$22965 ; p=0,818361$} \\
\hline & $\mathrm{F} 10.40(\mathrm{n}=25)$ & $1,17(0,93 ; 1,33)$ & 0,$08021 ; p=0,936069$ & \\
\hline \multirow[t]{3}{*}{ HT } & Контроль $(\mathrm{n}=35)$ & $1,90(1,77 ; 2,34)$ & & \multirow{3}{*}{3,$31358 ; \mathbf{p}=\mathbf{0 , 0 0 0 9 2 1}$} \\
\hline & $\mathrm{F} 20.0(\mathrm{n}=40)$ & $3,06(2,07 ; 4,06)$ & 4,$58779 ; \mathbf{p}=\mathbf{0 , 0 0 0 0 0 4}$ & \\
\hline & $\mathrm{F} 10.40(\mathrm{n}=25)$ & $2,1(1,78 ; 2,85)$ & 1,$96154 ; \mathbf{p}=\mathbf{0 , 0 4 9 8 1 7}$ & \\
\hline \multirow[t]{3}{*}{ MT } & Контроль $(\mathrm{n}=35)$ & $2,21(1,79 ; 2,71)$ & & \multirow{3}{*}{0,$66272 ; p=0,507512$} \\
\hline & F20.0 $(n=40)$ & $2,48(1,99 ; 3,85)$ & 1,$51864 ; p=0,128853$ & \\
\hline & $\mathrm{F} 10.40(\mathrm{n}=25)$ & $2,26(1,99 ; 2,83)$ & 1,$13755 ; p=0,255311$ & \\
\hline
\end{tabular}

П р и м е ч а н и е: жирным шрифтом выделены значимые результаты.

Показатели микроциркуляции крови пациентов с острой параноидной шизофренией и алкогольным делирием в динамике в процессе лечения

\begin{tabular}{|c|l|l|l|l|}
\hline $\begin{array}{c}\text { Показатель } \\
\text { (ед. измерения) }\end{array}$ & \multicolumn{1}{|c|}{ Группа } & \multicolumn{1}{|c|}{ До лечения } & Через 2 недели & $\begin{array}{c}\text { Критерий Вилкоксона } \\
\text { между группами }\end{array}$ \\
\hline \multirow{2}{*}{ ПМ (пф.ед.) } & F20.0 $(\mathrm{n}=40)$ & $6,88(5,13 ; 8,74)$ & $7,90(6,22 ; 10,12)$ & 2,$970527 ; \mathbf{p}=\mathbf{0 , 0 0 2 9 7 3}$ \\
\cline { 2 - 5 } & $\mathrm{F} 10.40(\mathrm{n}=25)$ & $9,37(7,78 ; 10,91)$ & $8,45(6,53 ; 10,05)$ & 2,$273119 ; \mathbf{p}=\mathbf{0 , 0 2 3 0 2 0}$ \\
\hline \multirow{2}{*}{ Кv (\%) } & $\mathrm{F} 20.0(\mathrm{n}=40)$ & $61,59(38,73 ; 80,86)$ & $63,61(47,93 ; 86,15)$ & 0,$914008 ; \mathrm{p}=0,360713$ \\
\cline { 2 - 5 } & $\mathrm{F} 10.40(\mathrm{n}=25)$ & $15,53(11,21 ; 33,4)$ & $21,18(9,05 ; 53,49)$ & 1,$968343 ; \mathbf{p}=\mathbf{0 , 0 4 9 0 2 9}$ \\
\hline \multirow{2}{*}{ (пф.ед.) } & $\mathrm{F} 20.0(\mathrm{n}=40)$ & $4,92(2,56 ; 6,71)$ & $3,82(2,14 ; 6,26)$ & 2,$009474 ; \mathbf{p}=\mathbf{0 , 0 4 4 4 4 8 8}$ \\
\cline { 2 - 5 } & $\mathrm{F} 10.40(\mathrm{n}=25)$ & $2,02(0,88 ; 3,51)$ & $2,32(0,68 ; 5,36)$ & 1,$054016 ; \mathrm{p}=0,291876$ \\
\hline \multirow{2}{*}{ ПШ } & $\mathrm{F} 20.0(\mathrm{n}=40)$ & $0,92(0,83 ; 1,09)$ & $1,06(0,84 ; 1,74)$ & 2,$449102 ; \mathbf{p}=\mathbf{0 , 0 1 4 3 3 2}$ \\
\cline { 2 - 5 } & $\mathrm{F} 10.40(\mathrm{n}=25)$ & $1,09(0,92 ; 1,39)$ & $1,17(0,93 ; 1,33)$ & 0,$050796 ; \mathrm{p}=0,959488$ \\
\hline \multirow{2}{*}{ НТ } & $\mathrm{F} 20.0(\mathrm{n}=40)$ & $2,09(1,91 ; 2,90)$ & $3,06(2,07 ; 4,06)$ & 3,$313280 ; \mathbf{p}=\mathbf{0 , 0 0 0 9 2 2}$ \\
\cline { 2 - 5 } & $\mathrm{F} 10.40(\mathrm{n}=25)$ & $1,81(1,60 ; 2,08)$ & $2,1(1,78 ; 2,85)$ & 2,$349313 ; \mathbf{p}=\mathbf{0 , 0 1 8 8 0 9}$ \\
\hline \multirow{2}{*}{ МТ } & $\mathrm{F} 20.0(\mathrm{n}=40)$ & $2,13(1,88 ; 2,75)$ & $2,48(1,99 ; 3,85)$ & 2,$721863 ; \mathbf{p}=\mathbf{0 , 0 0 6 4 2 2}$ \\
\cline { 2 - 5 } & $\mathrm{F} 10.40(\mathrm{n}=25)$ & $2,01(1,86 ; 2,27)$ & $2,26(1,99 ; 2,83)$ & 2,$654089 ; \mathbf{p}=\mathbf{0 , 0 0 7 9 5 3}$ \\
\hline
\end{tabular}

П р и м е ч а н и е: жирным шрифтом выделены значимые результаты.

При параноидной шизофрении зарегистрированы существенные изменения среднего колебания перфузии (б). Среднеквадратическое отклонение было максимальным в остром психотическом состоянии (превышение в 6,3 раза значений контрольной группы, $\mathrm{p}=0,0000)$, затем показатель уменьшался в процессе лечения $(\mathrm{p}=0,04)$, но все равно не достигал контрольных значений, по-прежнему превышая их в 4,8 раза $(\mathrm{p}=0,0000)$. У пациентов в состоянии алкогольного делирия среднее колебание перфузии превышало контрольные значения в 2,6-2,9 раза 
как в остром состоянии $(\mathrm{p}=0,001)$, так и после купирования психоза ( $<<0,008)$, показывая тенденцию к некоторому росту (табл. 1-2). При этом величина среднеквадратического отклонения была значимо ниже, чем при острой параноидной шизофрении ( $\mathrm{p}=0,001)$.

Показатель шунтирования в острый период психоза при шизофрении оказался сниженным ( $\mathrm{p}=0,001)$, однако через 2 недели произошло его увеличение до контрольных значений $(\mathrm{p}=0,01)$. При алкогольном делирии показатель шунтирования не отличался от аналогичного показателя в контрольной группе, хотя можно наблюдать тенденцию к его росту в процессе выхода из психоза (табл. 1-2).

Нейрогенный тонус прекапиллярных резистентных микрососудов был изначально увеличенным в 1,1 раза $(\mathrm{p}=0,02)$ в группе пациентов с шизофренией, демонстрируя рост в 1,5 раза в динамике $(\mathrm{p}=0,0009)$. Через 2 недели он превышал контрольные значения в 1,6 раза ( $\mathrm{p}=0,0000)$. У пациентов группы с алкогольным делирием увеличение нейрогенного тонуса наблюдалось только после купирования психоза (в 1,2 раза через 2 недели; $\mathrm{p}=0,001)$, формируя отличия от группы контроля в 1,1 раза $(\mathrm{p}=0,04)$. Исходный показатель не отличался от показателя контрольной группы.

Миогенный тонус метартериол и прекапиллярных сфинктеров в обеих группах пациентов был несколько ниже, чем в контрольной группе. Через 2 недели показатель увеличивался в $1,1-1,2$ раза ( $\mathrm{p}=0,006)$, хотя отличия оказались незначимыми от контрольных (табл. 1-2).

\section{ЗАКЛЮЧЕНИЕ}

Таким образом, при анализе полученных результатов выявлены существенные нарушения микроциркуляции у пациентов в остром психотическом состоянии при шизофрении и при алкогольном делирии. Наблюдаемые изменения при данных расстройствах носят выраженный и распространенный характер, они имеют как много общих черт, так и некоторые отличия.

Общие изменения выражаются в системном ускорении тока крови в единицу времени через микроциркуляторное русло, выраженных колебаниях перфузии и усилении локальных механизмов регуляции кровотока. Особенностью регистрируемых изменений при шизофрении являются изначально присутствующие сниженные показатели шунтирования при высоком нейрогенном тонусе прекапиллярных резистентных микрососудов и чрезмерно высокие показатели коэффициента вариации и среднего колебания перфузии, что свидетельствует о серьезном дисбалансе между медиаторами, обеспечивающими оптимальное течение локальных эндотелийзависимых процессов. В состоянии алкогольного делирия отмечены более выраженные системные нарушения микроциркуляции в виде серьезного ускорения тока крови в единицу времени и роста показателя шунтирования при менее выраженных, но тем не менее присутствующих нарушениях локальных механизмов регуляции кровотока.

Стоит отметить, что изменения многих показателей тока крови в микроциркуляторном русле, определяемых методом лазерной доплеровской флоуметрии, сохраняются даже через две недели терапии психотического расстройства или выхода из него. Вероятно, все это приводит к патологическому действию регистрируемых нарушений в течение более длительного времени, нежели период острого психотического состояния.

Полученные результаты нуждаются в уточнении при помощи лабораторных методов, что станет предметом дальнейших исследований.

\section{КОНФЛИКТ ИНТЕРЕСОВ}

Авторы заявляют об отсутствии возможных конфликтов интересов в связи с публикацией данной статьи.

\section{ИСТОЧНИК ФИНАНСИРОВАНИЯ}

Исследование не имело спонсорской финансовой поддержки, выполнялось в рамках Государственного задания Минздрава России на осуществление научных исследований и разработок.

\section{СООТВЕТСТВИЕ ПРИНЦИПАМ ЭТИКИ}

Исследование проведено с соблюдением норм современной биомедицинской этики и этических стандартов, разработанных в соответствии с Хельсинской декларацией BMA (протокол заседания Комитета по этике Читинской государственной медицинской академии № 74 от 06.11.2015).

\section{ЛИТЕРАТУРА}

1. Крыжановский Г.Н. Общая патофизиология нервной системы: руководство. М.: Медицина, $1997 ; 352$.

2. Афанасьев В.В. Алкогольный абстинентный синдром. СПб.: Интермедика. 2002; 336.

3. Пауков В.С., Ерохин Ю.А. Патологическая анатомия пьянства и алкоголизма. Архив патологии. 2004; 4: 3-9.

4. Пауков В.С. Структурно-функциональная концепция алкогольной болезни. Журнал неврологии и психиатрии имени С.С. Корсакова. 2007; 1: $8-11$ 
5. Билибин Д.П., Дворников В.Е. Патофизиология алкогольной болезни и наркоманий. М.: Университет дружбы народов, 1990; 104.

6. Пауков В.С., Ерохин Ю.А. Изменения крови при хронической алкогольной интоксикации. Российский психиатрический журнал. 2001; 5: 58-62.

7. Хохрина Н.Т., Гофман А.Г., Узбеков М.Г., Сорокина 3.Х. Сосудистая церебральная патология у больных алкогольной энцефалопатией, перенесших алкогольный делирий. Российский психиатрический журнал. 2006; 6: 38-40.

8. Шорманов С.В. Структурные изменения головного мозга человека в условиях острой алкогольной интоксикации. Архив патологии. 2004; 4: 9-13.

9. Галанкин Л.Н., Ливанов Г.А. Роль расстройств кровообращения в развитии изменений сознания при непсихотическом и делириозном синдроме отмены алкоголя. Журнал неврологии $u$ психиатрии им. С.С. Корсакова. 2004; 5: 15-19.

10. Сахаров А.В., Голыгина С.Е., Пляскина Е.В., Говорин Н.В. Состояние микроциркуляции при синдроме отмены алкоголя (неосложненном и осложненном делирием). Наркология. 2015; 8: 36-40.

11. Бохан Н.А., Пронин В.С. Состояние микроциркуляции и сосудистая реактивность при хронической интоксикации никотином, этанолом и опиоидами. Сибирский вестник психиатрии и наркологии. 2008; 2: 47-51.

12. Корякин А.М., Ещёва Л.А., Дементьева Л.А., Екимовских А.В., Коваленко В.М. Особенности эндотелиальной дисфункции у больных хроническим алкоголизмом. Сибирский медицинский журнал. 2011; 2: 66-70.

13. Сидоров П.И., Чумакова Г.Н., Соловьев А.Г., Кирпич И.А. Поражение тромбоцитарного звена гемостаза при алкогольном абстинентном синдроме и при острых алкогольных психозах. Вoпросы наркологии. 1996; 4: 29-32.

14. Bertola A., Park O., Gao B. Chronic plus binge ethanol feeding synergistically induces neutrophil infiltration and liver injury in mice: a critical role for E-selectin. Hepatology. 2013; 58(5): 1814 1823. https://doi.org/10.1002/hep.26419

15. Kaku B., Mizumo S., Ohsato K. Plasma endotelin-1 elevation associated with alcohol - induced variant angina. Jpn Circ J. 1999; 63(7): 554-8. https://doi.org/10.1253/jcj.63.554

16. Sacanella E., Estruch R., Badia E., Fernandez-Sola F., Nicolas J.M. Chronic alcohol consumption increases serum levels of circulating endothelial cell/leucocyte adhesion molecules E-selectin and ICAM-1. Alcohol \& Alcoholism. 1999; 34(5): 678684.

17. Сахаров А.В., Голыгина С.Е., Терешков П.П. Динамика некоторых показателей эндотелиальной дисфункции и нейромаркеров у больных алкогольной зависимостью при синдроме отме- ны алкоголя, неосложненном и осложненном делирием. Вопросы наркологии. 2017; 10: 53-63.

18. Maiorano G., Bartolomucci F., Contursi V. Noninvasive detection of vascular dysfunction in alcoholic patients. Am. J. Hypertens. 1999; 12(2): 137144. DOI: 10.1016/S0895-7061(98)00173-3

19. Puddey I.B., Zilkens R.R., Croft K.D., Beilin L.J. Alcohol and endothelial function: a brief review. Clin. Exp. Pharmacol. Physiol. 2001; 28: 10201024. http://www.biomedsearch.com/nih/Alcoholendothelial-function-brief-review/11903307.html

20. Brown S., Inskip H., Barraclough B. Causes of the excess mortality of schizophrenia. Br. Journal Psychiatry. 2000; 177: 212-217. http://www.ncbi.nlm.nih.gov/pubmed/11040880

21. Meyer J.M. Cardiovascular illness and hyperlipidemia in patients with schizophrenia. Medical illness and Schizophrenia. Washington, DC: American Psychiatric Press. Inc. 2003; 53-80.

22. Chen P.H., Tsai S.Y., Kuo C.J., Chung K.H., Huang S.H., Chen C.C. Physiological characteristics of patients with schizophrenia prematurely dying from circulatory diseases. Asia Pac Psychiatry. 2016; 8(3): 199-205. https://doi.org/10.1111/appy.12207

23. Berrocal-Izquierdo N., Bioque M., Bernardo M. Is cerebrovascular disease a silent condition in patients with chronic schizophrenia-related disorders? Int Clin. Psychopharmacol. 2017; 32(2): 80-86. DOI: 10.1097/YIC.0000000000000153

24. Medved V., Kuzman M., Jovanovic N., Grubisin J., Kuzman T. Metabolic syndrome in female patients with schizophrenia treated with second generation antipsychotics: a 3-month follow-up. Psychopharmacology. 2008; 23(8): 915-922. http://www.biomedsearch.com/nih/Metabolicsyndrome-in-female-patients/18635691.html

25. Горобец Л.Н., Буланов В.С., Василенко Л.М., Литвинов А.В., Иванова Г.П., Поляковская Т.П. Нейролептические метаболические нарушения при лечении антипсихотическими средствами нового поколения. Журнал неврологии и психиатрии им. С.С. Корсакова. 2014; 114(2): 59-68.

26. Protopopova D., Masopust J., Malý R., Valis M., Dostalova G., Ranna K., Bažant J. Peripheral endothelial dysfunction as a marker of cardiovascular risk in physically healthy patients with schizophrenia and related psychoses: a matched case control study. Neuro Endocrinol Lett. 2014; 35(6): 503509.

27. Burghardt K., Grove T., Ellingrod V. Endothelial nitric oxide synthetase genetic variants, metabolic syndrome and endothelial function in schizophrenia. J. Psychopharmacol. 2014; 28(4): 349-356. doi: 10.1177/0269881113516200

28. Васильева А.И., Говорин Н.В. Нейромаркеры и показатели эндотелиальной дисфункции у пациентов в клинике первого психотического эпизода [Электронный ресурс]. Забайкальский медицинский вестник. 2011; 1: 26-32. Режим доступа: http://medacadem.chita.ru/zmv 
29. Israel A.K., Seeck A., Boettger M.K., Rachow T., Berger S., Voss A., Bär K.J. Peripheral endothelial dysfunction in patients suffering from acute schizophrenia: a potential marker for cardiovascular morbidity? Schizophr Res. 2011; 128(1-3): 44-50. https://doi.org/10.1016/j.schres.2011.02.007
30. Лазерная допплеровская флоуметрия микроциркуляции крови: руководство для врачей / под редакцией А.И. Крупаткина, В.В. Сидорова. М.: Медицина. 2005; 256.

Поступила в редакцию 28.01.2018 Утверждена к печати 8.04.2019

Сахаров Анатолий Васильевич - д.м.н., доцент, заведующий кафедрой психиатрии, наркологии и медицинской психологии ФГБОУ ВО «Читинская государственная медицинская академия» Минздрава России.

Озорнин Александр Сергеевич - к.м.н., заведующий отделением клиники первого психотического эпизода ГКУЗ «Краевая клиническая психиатрическая больница им. В.Х. Кандинского», ассистент кафедры психиатрии, наркологии и медицинской психологии ФГБОУ ВО «Читинская государственная медицинская академия» Минздрава России.

Голыгина Светлана Евгеньевна - ассистент кафедры психиатрии, наркологии и медицинской психологии ФГБОУ ВО «Читинская государственная медицинская академия» Минздрава России, врач психиатр-нарколог ГАУЗ «Забайкальский краевой наркологический диспансер».

Сахаров Анатолий Васильевич, sawt@list.ru

УДК 616.895.8:616.89-008.441.13:611.018.74

For citation: Sakharov A.V., Ozornin A.S., Golygina S.E. Parameters of blood microcirculation in patients with acute schizophrenia and delirium tremens in a comparative aspect. Siberian Herald of Psychiatry and Addiction Psychiatry. 2019; 2 (103): 13-21. https://doi.org/10.26617/1810-3111-2019-2(103)-13-21

\section{Parameters of blood microcirculation in patients with acute schizophrenia and delirium tremens in a comparative aspect}

\section{Sakharov A.V.1, Ozornin A.S. ${ }^{1,2}$, Golygina S.E. ${ }^{1,3}$}

${ }^{1}$ Chita State Medical Academy

Gorky Street 39-a, 672000, Chita, Russian Federation

${ }^{2}$ V.Kh. Kandinsky Territorial Clinical Psychiatric Hospital

Okruzhnoj proezd 3, 672042, Chita, Russian Federation

${ }^{3}$ Trans-Baikal Regional Narcological Dispensary

Verkholenskaya Street 1, 672039, Chita, Russian Federation

\section{ABSTRACT}

The pathogenesis of microcirculation disorders in mental and narcological disorders is not well understood. The aim of the work is to study the state of microcirculation of blood by the method of laser Doppler flowmetry in patients in a psychotic state with schizophrenia and with alcohol withdrawal syndrome with delirium in a comparative aspect. 40 patients with schizophrenia and 25 patients with delirium tremens in an acute psychotic state and after 2 weeks of therapy are examined using a laser blood flow analyzer. The control group consists of 35 healthy volunteers. General and systemic microcirculation disorders in patients with acute psychotic state in schizophrenia and delirium tremens in the form of accelerated blood flow per unit of time and excessive strengthening of local mechanisms of its regulation are established. At the same time, changes in microcirculation indices persist even after two weeks of therapy, having probably a longer pathological effect than the course of acute psychosis itself.

Keywords: schizophrenia, alcoholism, paranoid schizophrenia, delirium tremens, microcirculation, endothelial dysfunction.

\section{REFERENCES}

1. Kryzhanovsky G.N. Obshhaya patofiziologiya nervnoj sistemy [General pathophysiology of nervous system: management]. Moscow: Medicine, 1997; 325 (in Russian).

2. Afanas'ev V.V. Alkogol'nyj abstinentnyj sindrom [Alcohol withdrawal syndrome]. Sankt Peterburg: Intermedika, 2002; 336 (in Russian).
3. Paukov V.S., Erokhin Yu.A. Patologicheskaya anatomiya p'yanstva i alkogolizma [Pathological anatomy of drinking and alcoholism]. Arkhiv patologii - Archive of Pathology. 2004; 4: 3-9 (in Russian).

4. Paukov V.S. Strukturno-funktsional'naya kontseptsiya alkogol'noj bolezni [The structural-functional concept of an alcoholic disease]. Zhurnal nevrologii $i$ 
psikhiatrii imeni S.S. Korsakova - S.S. Korsakov Journal of Neurology and Psychiatry. 2007; 1: 8-11 (in Russian).

5. Bilibin D.P., Dvornikov V.E. Patofiziologiya alkogol'noj bolezni i narkomanij [Pathophysiology of an alcoholic disease and drug addiction]. Moscow: Peoples' Friendship University, 1990: 104 (in Russian).

6. Paukov V.S., Erokhin Yu.A. Izmeneniya krovi pri khronicheskoj alkogol'noj intoksikatsii [Changes of blood under chronic alcohol intoxication] Rossijskij psikhiatricheskij zhurnal - Russian Journal of Psychiatry. 2001; 5: 58-62 (in Russian).

7. Khokhrina N.T., Gofman A.G., Uzbekov M.G., Sorokina Z.Kh. Sosudistaya tserebral'naya patologiya u bol'nykh alkogol'noj ehntsefalopatiej, perenesshikh alkogol'nyj delirij [Vascular cerebral pathology in patients with alcoholic encephalopathy who have suffered from delirium tremens]. Rossijskij psikhiatricheskij zhurnal - Russian Journal of Psychiatry. 2006; 6: 38-40 (in Russian).

8. Shormanov S.V. Strukturnye izmeneniya golovnogo mozga cheloveka $\mathrm{V}$ usloviyakh ostroj alkogol'noj intoksikatsii [Structural changes in the human brain in conditions of acute alcohol intoxication]. Arkhiv patologii - Archives of Pathology. 2004; 4: 9-13 (in Russian).

9. Galankin L.N., Livanov G.A. Rol' rasstrojstv krovoobrashheniya $\mathrm{v}$ razvitii izmenenij soznaniya pri nepsikhoticheskom i delirioznom syndrome otmeny alkogolya [The role of circulatory disorders in the development of changes in consciousness in non-psychotic and delirious alcohol withdrawal syndrome]. Zhurnal nevrologii i psikhiatrii imeni S.S. Korsakova - S.S. Korsakov Journal of Neurology and Psychiatry. 2004; 5: 15-19 (in Russian).

10. Sakharov A.V., Golygina S.E., Plyaskina E.V., Govorin N.V. Sostoyanie mikrotsirkulyatsii pri syndrome otmeny alkogolya (neoslozhnennom i oslozhnennom deliriem) [The state of microcirculation in alcohol withdrawal syndrome (uncomplicated and complicated by delirium)]. Narkologiya Narcology. 2015; 8: 36-40 (in Russian).

11. Bokhan N.A., Pronin V.S. Sostoyanie mikrotsirkulyatsii i sosudistaya reaktivnost' pri khronicheskoj intoksikatsii nikotinom, ehtanolom i opioidami [The state of microcirculation and vascular reactivity in chronic intoxication with nicotine, ethanol and opioids]. Sibirskij vestnik psikhiatrii $i$ narkologii Siberian Herald of Psychiatry and Addiction Psychiatry. 2008; 2: 47-51 (in Russian).

12. Koryakin A.M., Eshhyova L.A., Dement'eva L.A., Ekimovskikh A.V., Kovalenko V.M. Osobennosti ehndotelial'noj disfunktsii u bol'nykh khronicheskim alkogolizmom [Features of endothelial dysfunction in patients with chronic alcoholism]. Sibirskij meditsinskij zhurnal - Siberian Medical Journal. 2011; 2: 66-70 (in Russian).

13. Sidorov P.I., Chumakova G.N., Solov'ev A.G., Kirpich I.A. Porazhenie trombotsitarnogo zvena gemo- staza pri alkogol'nom abstinentnom syndrome i pri ostrykh alkogol'nykh psikhozakh [The defeat of platelet hemostasis in alcohol withdrawal syndrome and in acute alcoholic psychosis]. Voprosy narkologii - Journal of Addiction Problems. 1996; 4: 29-32 (in Russian).

14. Bertola A., Park O., Gao B. Chronic plus binge ethanol feeding synergistically induces neutrophil infiltration and liver injury in mice: a critical role for E-selectin. Hepatology. 2013; 58(5): 18141823. https://doi.org/10.1002/hep.26419

15. Kaku B., Mizumo S., Ohsato K. Plasma endotelin-1 elevation associated with alcohol - induced variant angina. Jpn Circ J. 1999; 63(7): 554-8. https://doi.org/10.1253/jcj.63.554

16. Sacanella E., Estruch R., Badia E., Fernandez-Sola F., Nicolas J.M. Chronic alcohol consumption increases serum levels of circulating endothelial cell/leucocyte adhesion molecules E-selectin and ICAM-1. Alcohol \& Alcoholism. 1999; 34(5): 678684.

17. Sakharov A.V., Golygina S.E., Tereshkov P.P. Dinamika nekotorykh pokazatelej ehndotelial'noj disfunktsii i nejromarkerov u bol'nykh alkogol'noj zavisimost'yu pri syndrome otmeny alkogolya, neoslozhnennom i oslozhnennom delirium [The dynamics of some indicators of endothelial dysfunction and neuromarkers in patients with alcohol dependence in alcohol withdrawal syndrome, uncomplicated and complicated by delirium]. Voprosy narkologii - Journal of Addiction Problems. 2017; 10: 53-63 (in Russian).

18. Maiorano G., Bartolomucci F., Contursi V. Noninvasive detection of vascular dysfunction in alcoholic patients. Am. J. Hypertens. 1999; 12(2): 137144. DOI: 10.1016/S0895-7061(98)00173-3

19. Puddey I.B., Zilkens R.R., Croft K.D., Beilin L.J. Alcohol and endothelial function: a brief review. Clin. Exp. Pharmacol. Physiol. 2001; 28: 10201024. http://www.biomedsearch.com/nih/Alcoholendothelial-function-brief-review/11903307.html

20. Brown S., Inskip H., Barraclough B. Causes of the excess mortality of schizophrenia. Br. Journal Psychiatry. 2000; 177: 212-217. http://www.ncbi.nlm.nih.gov/pubmed/11040880

21. Meyer J.M. Cardiovascular illness and hyperlipidemia in patients with schizophrenia. Medical illness and Schizophrenia. Washington, DC: American Psychiatric Press. Inc. 2003; 53-80.

22. Chen P.H., Tsai S.Y., Kuo C.J., Chung K.H., Huang S.H., Chen C.C. Physiological characteristics of patients with schizophrenia prematurely dying from circulatory diseases. Asia Pac Psychiatry. 2016; 8(3): 199-205. https://doi.org/10.1111/appy.12207

23. Berrocal-Izquierdo N., Bioque M., Bernardo M. Is cerebrovascular disease a silent condition in patients with chronic schizophrenia-related disorders? Int Clin. Psychopharmacol. 2017; 32(2): 80-86. DOI: 10.1097/YIC.0000000000000153 
24. Medved V., Kuzman M., Jovanovic N., Grubisin J., Kuzman T. Metabolic syndrome in female patients with schizophrenia treated with second generation antipsychotics: a 3-month follow-up. Psychopharmacology. 2008; 23(8): 915-922. http://www.biomedsearch.com/nih/Metabolicsyndrome-in-female-patients/18635691.html

25. Gorobets L.N., Bulanov V.S., Vasilenko L.M., Litvinov A.V., Ivanova G.P., Polyakovskaya T.P. Nejrolepticheskie metabolicheskie narusheniya pri lechenii antipsikhoticheskimi sredstvami novogo pokoleniya [Neuroleptic metabolic disorders in the treatment with new generation antipsychotics]. Zhurnal nevrologii i psikhiatrii imeni S.S. Korsakova - S.S. Korsakov Journal of Neurology and Psychiatry. 2014; 114(2): 59-68 (in Russian).

26. Protopopova D., Masopust J., Malý R., Valis M., Dostalova G., Ranna K., Bažant J. Peripheral endothelial dysfunction as a marker of cardiovascular risk in physically healthy patients with schizophrenia and related psychoses: a matched case control study. Neuro Endocrinol Lett. 2014; 35(6): 503509.

27. Burghardt K., Grove T., Ellingrod V. Endothelial nitric oxide synthetase genetic variants, metabolic syndrome and endothelial function in schizophre- nia. J. Psychopharmacol. 2014; 28(4): 349-356. doi: 10.1177/0269881113516200

28. Vasil'eva A.I., Govorin N.V. Nejromarkery I pokazateli ehndotelial'noj disfunktsii u patsientov v klinike pervogo psikhoticheskogo ehpizoda [Neuromarkers and indicators of endothelial dysfunction in patients in the clinic of the first psychotic episode] [Electronic Resource]. Zabajkal'skij meditsinskij vestnik - Trans-Baikal Medical Bulletin. 2011; 1: 26-32/ Access Mode: http://medacadem.chita.ru/zmv (in Russian).

29. Israel A.K., Seeck A., Boettger M.K., Rachow T., Berger S., Voss A., Bär K.J. Peripheral endothelial dysfunction in patients suffering from acute schizophrenia: a potential marker for cardiovascular morbidity? Schizophr Res. 2011; 128(1-3): 44-50. https://doi.org/10.1016/j.schres.2011.02.007

30. Lazernaya dopplerovskaya floumetriya mikrotsirkulyatsii krovi: rukovodstvo dlya vrachej [Laser Doppler flowmetry of microcirculation of blood: a guide for physicians]. A.I. Krupatkin, V.V. Sidorov, eds. Moscow: Medicine, 2005; 256 (in Russian).

Received January 28.2018 Accepted April 08.2019

Sakharov Anatoly V. - MD, Associate Professor, Head of the Department of Psychiatry, Narcology and Medical Psychology, Chita State Medical Academy, Chita, Russian Federation.

Ozornin Alexander S. - PhD, Head of the Clinic of the First Psychotic Episode V.Kh. Kandinsky Territorial Clinical Psychiatric Hospital, Assistant of the Department of Psychiatry, Narcology and Medical Psychology of the Chita State Medical Academy, Chita, Russian Federation.

Golygina Svetlana E. - Assistant of the Department of Psychiatry, Narcology and Medical Psychology at the Chita State Medical Academy, Doctor of Trans-Baikal Regional Narcological Dispensary, Chita, Russian Federation.

Sakharov Anatoly V., sawt@list.ru 